\title{
Integration of Thermal Treatment and Extrusion by Compounding for Processing Various Wastes for Energy Applications
}

Shreyas S. Kolapkar, ${ }^{+}$Stas Zinchik, ${ }^{+}$Zhuo Xu, ${ }^{+}$Armando G. McDonald, ${ }^{\#}$ Ezra Bar-Ziv ${ }^{+}{ }^{*}$

+Department of Mechanical Engineering - Engineering Mechanics, Michigan Technological University, Houghton, Michigan, 49931, United States.

\#Department of Forest, Rangeland and Fire Sciences, University of Idaho, Moscow, Idaho, 83844, United States.

*Corresponding Author Email: ebarziv@mtu.edu

Appendix I

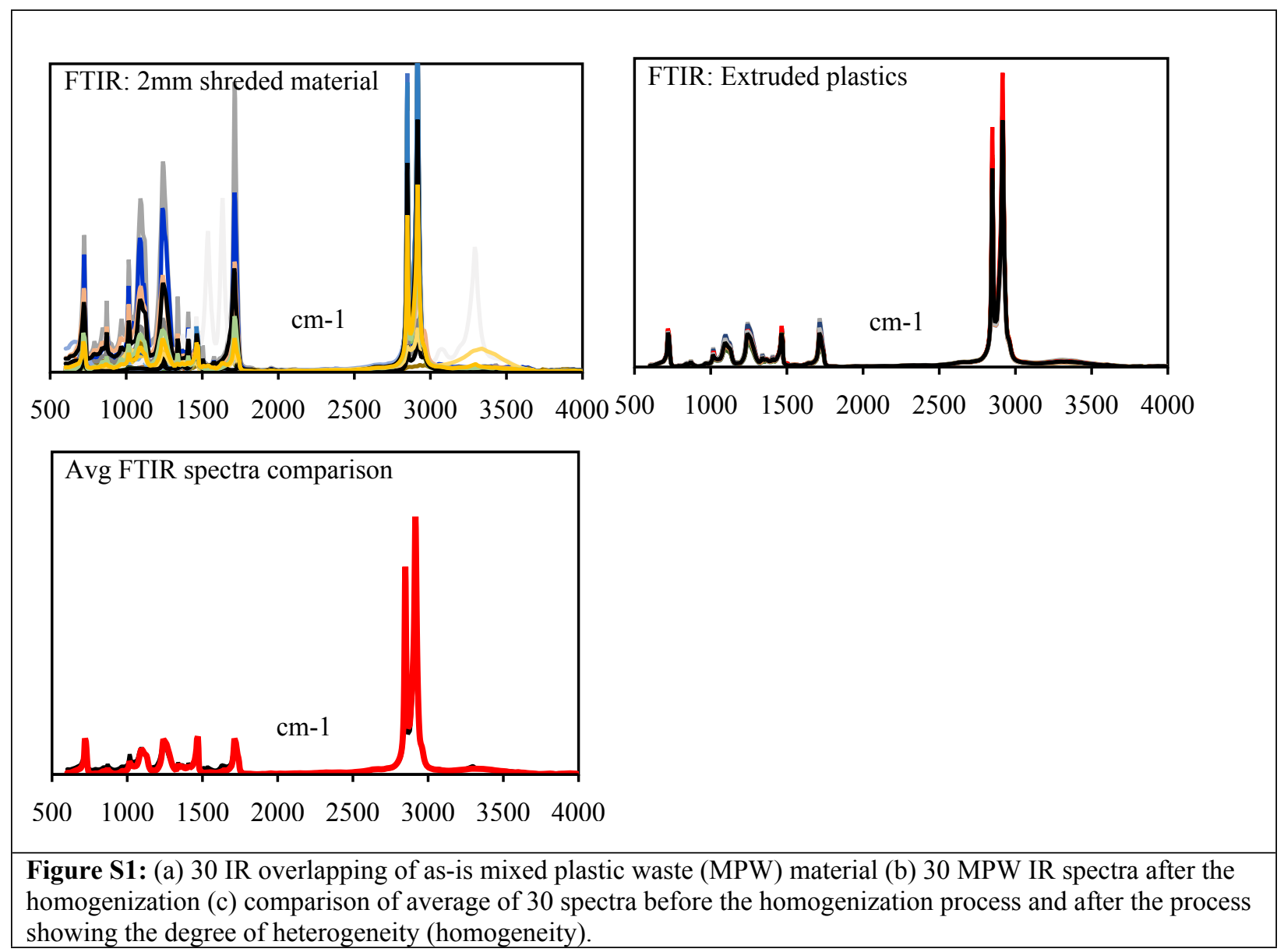


Table S1: Proximate, ultimate and ash analysis of $60 \%$ fiber - 40\%plastic material feedstock (non-torrefied). ${ }^{1}$

\begin{tabular}{|l|c|c|c|}
\hline Proximate & Values & Ash & Values, \% \\
\hline Moisture, \% & $3.3 \pm 0.5$ & $\mathrm{SiO}_{2}$ & $33 \pm 18$ \\
\hline Ash, \% & $6.0 \pm 0.6$ & $\mathrm{~A}_{2} \mathrm{O}_{3}$ & $27 \pm 11$ \\
\hline Volatiles, \% & $83.5 \pm 2.6$ & $\mathrm{TiO}_{2}$ & $7.2 \pm 3.4$ \\
\hline Fixed Carbon, \% & $7.2 \pm 2.0$ & $\mathrm{Fe}_{2} \mathrm{O}_{3}$ & $0.9 \pm 0.9$ \\
\hline Sulfur, \% & $0.2 \pm 0.1$ & $\mathrm{CaO}$ & $21 \pm 12$ \\
\hline $\mathrm{HHV,} \mathrm{MJ/kg}$ & $26.10 \pm 1.05$ & $\mathrm{MgO}$ & $3.0 \pm 3.0$ \\
\hline & & $\mathrm{K}_{2} \mathrm{O}$ & $0.6 \pm 0.4$ \\
\hline Ultimate & Values, \% & $\mathrm{Na}_{2} \mathrm{O}$ & $1.6 \pm 0.7$ \\
\hline Carbon & $55.4 \pm 1.8$ & $\mathrm{MnO}$ & $0.02 \pm 0.01$ \\
\hline Hydrogen & $7.9 \pm 0.3$ & $\mathrm{BaO}$ & $0.2 \pm 0.2$ \\
\hline Nitrogen & $0.3 \pm 0.1$ & Others & $2.8 \pm 1.4$ \\
\hline Oxygen & $27.1 \pm 1.6$ & & \\
\hline
\end{tabular}

Table S2: Proximate analysis of torrefied 60\% fiber and 40\% plastic material (moisture-free basis).

\begin{tabular}{|c|c|c|c|c|c|}
\hline $\begin{array}{c}\text { Mass } \\
\text { Loss }\end{array}$ & $\begin{array}{c}\text { Ash } \\
\text { Content } \\
\text { (wt \%) }\end{array}$ & $\begin{array}{c}\text { Volatile } \\
\text { Matter } \\
\text { (wt \%) }\end{array}$ & $\begin{array}{c}\text { Fixed } \\
\text { Carbon } \\
\text { by difference }\end{array}$ & $\begin{array}{c}\text { Sulfur } \\
\text { (wt \%) }\end{array}$ & $\begin{array}{c}\mathbf{S O}_{2} \\
(\mathbf{l b} / \mathbf{m m b t u})\end{array}$ \\
\hline $0 \%$ & $5.0 \%$ & $87.8 \%$ & $7.1 \%$ & $0.032 \%$ & 0.050 \\
\hline $10 \%$ & $4.6 \%$ & $81.3 \%$ & $13.9 \%$ & $0.041 \%$ & 0.066 \\
\hline $30 \%$ & $7.3 \%$ & $67.7 \%$ & $24.9 \%$ & $0.047 \%$ & 0.074 \\
\hline $50 \%$ & $8.8 \%$ & $60.9 \%$ & $30.2 \%$ & $0.050 \%$ & 0.008 \\
\hline
\end{tabular}

Table S3: Specific Power Consumption for various pelletizing processes

\begin{tabular}{|l|l|l|l|l|}
\hline$\#$ & Process & Feedstock Used & $\begin{array}{l}\text { Specific Energy } \\
\text { Consumption }\end{array}$ & Source \\
\hline 1 & $\begin{array}{l}\text { Integrated torrefaction Extrusion } \\
\text { Pellets produced with density of } 1000- \\
1140 \mathrm{~kg} / \mathrm{m}^{3} \text { and durability of } 98.27 \pm 0.56 \% .\end{array}$ & $\begin{array}{l}60 \% \text { Fiber- } 40 \% \\
\text { Plastic }\end{array}$ & $\begin{array}{l}90 \mathrm{kWh} / \mathrm{ton} \text { at } 50 \\
\mathrm{~kg} / \mathrm{h} .\end{array}$ & Current Study \\
\hline 2 & $\begin{array}{l}\text { Die Pellet mill } \\
\text { Pellet mill with die speed of } 60 \mathrm{~Hz} \text {; preheating at } \\
90^{\circ} \mathrm{C}, \text { pellets density of } 544 \mathrm{~kg} / \mathrm{m}^{3} \text { and } \\
\text { durability of } 95.69 \%\end{array}$ & $\begin{array}{l}\text { Woody biomass } \\
\text { with } 33 \% \\
\text { moisture }\end{array}$ & $\sim 116 \mathrm{kWh} / \mathrm{ton}$ & $\begin{array}{l}\text { Tumuluru et } \\
\text { al. }^{2}\end{array}$ \\
\hline 3 & Hammer mill and ring die press & Hay Pellets & $157 \mathrm{kWh} /$ ton & Kirsten et al. ${ }^{3}$ \\
\hline
\end{tabular}

\section{References}

(1) Xu, Z.; Zinchik, S.; Kolapkar, S. S.; Bar-Ziv, E.; Hansen, T.; Conn, D.; McDonald, A. G. Properties of Torrefied U.S. Waste Blends. Front. Energy Res. 2018, 6 (July), 1-13. https://doi.org/10.3389/fenrg.2018.00065.

(2) Tumuluru, J. S. Specific Energy Consumption and Quality of Wood Pellets Produced Using High-Moisture Lodgepole Pine Grind in a Flat Die Pellet Mill. Chem. Eng. Res. Des. 2016, 110, 82-97. https://doi.org/10.1016/j.cherd.2016.04.007.

(3) Kirsten, C.; Lenz, V.; Schröder, H. W.; Repke, J. U. Hay Pellets - The Influence of Particle Size Reduction on Their Physical-Mechanical Quality and Energy Demand during Production. Fuel Process. Technol. 2016, 148, 163-174. https://doi.org/10.1016/j.fuproc.2016.02.013. 